\title{
APLICAÇÃO DE WAVELETS NA ANÁLISE DE RÁDIO EMISSÕES SOLARES TIPO III MÉTRICAS
}

\section{Humberto Gimenes Macedo ${ }^{1}$ Francisco Carlos Rocha Fernandes ${ }^{2}$}

Resumo: Séries temporais associadas a explosões solares são classificadas como séries não estacionárias, assim sendo, suas componentes de frequência apresentam uma variação ao longo do tempo. Dessa maneira, torna-se necessário aplicar a transformada wavelet, pois ela concebe uma representação tempo-frequência, possibilitando identificar períodos em determinados intervalos de tempo, de forma a caracterizar o evento físico. Aplicou-se a técnica wavelet em duas séries temporais de um grupo de emissões tipo III registradas pelo espectrógrafo BLEN7M em 21 de abril de 2015 (08:30:00 UT - 09:00:00 UT), na faixa de ondas métricas (200 MHz - $800 \mathrm{MHz})$. Os resultados demonstram períodos entre 8 e 16 segundos em um mesmo subgrupo de emissões e dezenas de segundos (60 a 120 segundos) entre grupos. A configuração na qual os períodos apareceram nos resultados, sugerem que os eventos físicos responsáveis pela emissão do tipo III tem natureza intermitente.

Palavras-chave: Wavelet, Séries temporais, Rádio emissão solar tipo III.

\footnotetext{
${ }^{1}$ Engenharia de Computação/Universidade do Vale do Paraíba, Brasil. E-mail: gimeneshumberto@outlook.com.

2 Laboratório de Física e Astronomia/Universidade do Vale do Paraíba, Brasil. E-mail: guga@univap.br.
} 